\title{
Divulgación Científica
}

\section{Nomenclatura de compuestos que tienen átomos de nitrógeno}

Este documento (tercera parte) es una versión de las recomendaciones dadas por la IUPAC, 1979, para la nomenclatura de compuestos nitrogenados

http://www.acdlabs.com/iupac/nomenclature/

\section{Nitrilos}

$\underline{\text { Regla C }-832}$

En la nomenclatura sustitutiva, los nitrilos se nombran utilizando los siguientes métodos:

832.1 Los compuestos RCN, en los que el átomo de nitrógeno con un triple enlace, remplaza los tres átomos de hidrógeno del átomo de carbono final de una cadena de un hidrocarburo acíclico, se nombran añadiendo los términos "nitrilo" 0 "dinitrilo" al nombre del hidrocarburo<smiles>CCCCCC#N</smiles>

Hexanonitrilo<smiles>N#CCCCCC#N</smiles>

Hexanodinitrilo

Tenga en cuenta: Aquí y en la regla $\mathbf{C}$ 832.3, el término "nitrilo" indica el triple enlace del átomo de nitrógeno y no se refiere al átomo de carbono enlazado a él. La numeración de la cadena carbonada se inicia en este átomo de carbono.
832.2 Si los compuestos RCN se consideran como derivados de los ácidos, $\mathrm{RCOOH}$, en cuyo nombre sistemático se utilizan los términos "ácido carbocíclico", se nombran sustituyendo estos términos por

\section{"carbonitrilo"}

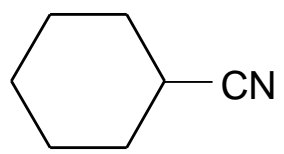

Ciclohexanocarbonitrilo<smiles>N#CCCCC(C#N)CCC#N</smiles>

\subsection{6 - Hexanotricarbonitrilo}<smiles>N#Cc1nccs1</smiles>

2 - Tiazolcarbonitrilo 
832.3 Si los compuestos RCN se consideran como derivados de los ácidos, $\mathrm{RCOOH}$, en cuyo nombre trivial se utilizan "ácido" y "oico", "ácido" "ico" se nombran sustituyendo estos términos por "onitrilo

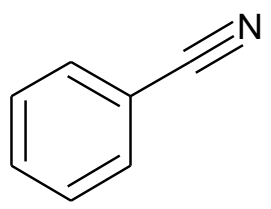

\section{Benzonitrilo}

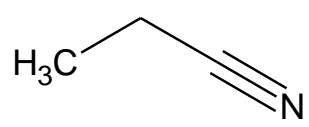

Propionitrilo

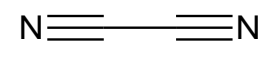

Oxalonitrilo

832.4 Si se utiliza el procedimiento radicofuncional para nombrar los compuestos RCN, se da el nombre del radical seguido por el término "cianuro" para el grupo -CN.<smiles>CCC#N</smiles>

Cianuro de Etilo

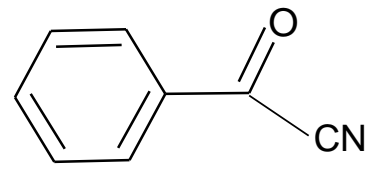

Cianuro de Benzoilo

832.5 Cuando el compuesto, además de tener el grupo $\mathrm{CN}$, tiene otro grupo de mayor prioridad, el grupo CN se denomina "ciano"<smiles>N#Cc1ccc(C(=O)O)o1</smiles>

Ácido 5-ciano - furoico<smiles>N#Cc1ccc(C(N)=O)c(C#N)c1</smiles>

2,4-dicianobenzamida 